\title{
Formulation of Quaternized Aminated Chitosan Nanoparticles for Efficient Encapsulation and Slow Release of Curcumin
}

\author{
Ahmed M. Omer ${ }^{1, *}$, Zyta M. Ziora ${ }^{2}{ }^{(D}$, Tamer M. Tamer ${ }^{1}$, Randa E. Khalifa ${ }^{1}$, Mohamed A. Hassan ${ }^{3}{ }^{(\mathbb{D},}$ \\ Mohamed S. Mohy-Eldin ${ }^{1}$ and Mark A. T. Blaskovich ${ }^{2}$ D \\ 1 Polymer Materials Research Department, Advanced Technology and New Materials Research \\ Institute (ATNMRI), City of Scientific Research and Technological Applications (SRTA-City), \\ New Borg El-Arab City, Alexandria 21934, Egypt; ttamer85@gmail.com (T.M.T.); \\ randaghonim@yahoo.com (R.E.K.); mmohyeldin@srtacity.sci.eg (M.S.M.-E.) \\ 2 Centre for Superbug Solutions, Institute for Molecular Bioscience, The University of Queensland, \\ Brisbane, QLD 4072, Australia; z.ziora@uq.edu.au (Z.M.Z.); m.blaskovich@uq.edu.au (M.A.T.B.) \\ 3 Protein Research Department, Genetic Engineering and Biotechnology Research Institute (GEBRI), \\ City of Scientific Research and Technological Applications (SRTA-City), New Borg El-Arab City, \\ Alexandria 21934, Egypt; madel@srtacity.sci.eg \\ * Correspondence: amomar@srtacity.sci.eg; Tel.: +20-3-4593414
}

Citation: Omer, A.M.; Ziora, Z.M.; Tamer, T.M.; Khalifa, R.E.; Hassan, M.A.; Mohy-Eldin, M.S.; Blaskovich, M.A.T. Formulation of Quaternized Aminated Chitosan Nanoparticles for Efficient Encapsulation and Slow

Release of Curcumin. Molecules 2021, 26, 449. https://doi.org/ $10.3390 /$ molecules 26020449

Academic Editor: Maria

Camilla Bergonzi

Received: 16 December 2020

Accepted: 12 January 2021

Published: 16 January 2021

Publisher's Note: MDPI stays neutral with regard to jurisdictional clai$\mathrm{ms}$ in published maps and institutional affiliations.

Copyright: $\odot 2021$ by the authors. Licensee MDPI, Basel, Switzerland. This article is an open access article distributed under the terms and conditions of the Creative Commons Attribution (CC BY) license (https:// creativecommons.org/licenses/by/ $4.0 /)$.

\begin{abstract}
An effective drug nanocarrier was developed on the basis of a quaternized aminated chitosan (Q-AmCs) derivative for the efficient encapsulation and slow release of the curcumin (Cur)-drug. A simple ionic gelation method was conducted to formulate Q-AmCs nanoparticles (NPs), using different ratios of sodium tripolyphosphate (TPP) as an ionic crosslinker. Various characterization tools were employed to investigate the structure, surface morphology, and thermal properties of the formulated nanoparticles. The formulated Q-AmCs NPs displayed a smaller particle size of $162 \pm 9.10 \mathrm{~nm}$, and higher surface positive charges, with a maximum potential of $+48.3 \mathrm{mV}$, compared to native aminated chitosan (AmCs) NPs $(231 \pm 7.14 \mathrm{~nm},+32.8 \mathrm{mV})$. The Cur-drug encapsulation efficiency was greatly improved and reached a maximum value of $94.4 \pm 0.91 \%$, compared to $75.0 \pm 1.13 \%$ for AmCs NPs. Moreover, the in vitro Cur-release profile was investigated under the conditions of simulated gastric fluid [SGF; $\mathrm{pH}$ 1.2] and simulated colon fluid [SCF; $\mathrm{pH} 7.4$ ]. For Q-AmCs NPs, the Cur-release rate was meaningfully decreased, and recorded a cumulative release value of $54.0 \%$ at $\mathrm{pH} 7.4$, compared to $73.0 \%$ for AmCs NPs. The formulated nanoparticles exhibited acceptable biocompatibility and biodegradability. These findings emphasize that Q-AmCs NPs have an outstanding potential for the delivery and slow release of anticancer drugs.
\end{abstract}

Keywords: nanoparticles; quaternized aminated chitosan; curcumin slow release

\section{Introduction}

Drug delivery systems (DDSs) are pharmaceutical formula or devices designed to overcome the present limitations of conventional therapeutics [1]. DDSs have the ability to improve the biological activity, enhance the therapeutic index or extend the biological half-life of drugs [2,3]. Various materials including microspheres, mesoporous, micro/nanoparticles, liposomes, micelles, and emulsions were developed as effective drug carriers [4]. Currently, a wide range of nanoparticles are being advanced to serve as potential carriers for delivering drugs in a controlled mode to specific-targeted sites in the human body [5-8]. These nano-sized systems have a remarkable aptitude for the targeted delivery of a specific drug dose to specific cells (such as cancer cells), without disturbing the physiology of the normal cells [9]. In addition, the targeted nano systems are able to ameliorate poor drug diffusion/release profiles, improve drug solubility, and boost bio-distribution and immunogenicity [10].

Chitosan (Cs), a natural biopolymer, is derived from chitin, which is the main component for the exoskeleton of crabs, shrimps, and lobsters [11]. Chitosan is composed 
of $\beta$-(1,4)-2-acetamido-D-glucose and $\beta$-(1,4)-2-amino-D-glucose groups, and possesses a polycationic character. Due to its intriguing bio-characteristics, such as biocompatibility, biodegradability, non-toxicity, and bioavailability [12], Cs are selected as an ideal candidate for several medical and pharmaceutical applications, including wound dressing, tissue engineering, and drug delivery systems $[13,14]$. Furthermore, Cs have the capability to form gel-nanoparticles via ionic crosslinking with polyanionic molecules, such as sodium tri-polyphosphate (TPP) [15]. Cs are also established as a nanoscopic carrier for diverse drugs, with chitosan-based nanoparticles (NPs) evolving to be one of the most accepted delivery systems for cancer chemotherapy [16,17]. Numerous chemical modifications, including the Schiff base formation [18], grafting [19], and quaternization [20], were conducted on native chitosan to broaden the spectrum of its biological activities. For instance, amine-functionalized chitosan (aminated chitosan; AmCs) is a newly developed chitosan derivative with extra amine groups, which displays better anti-microbial activity, decent blood biocompatibility, and biodegradability [21]. Consequently, an AmCs derivative was been successfully employed as an effective candidate for advanced wound dressing and oral drug delivery systems [22,23].

Recently, close attention was paid to the modified water-soluble forms of chitosan derivatives, since their improved characteristics can play an important role in the pharmaceutical fields [24]. Among these modifications, quaternization of Cs can significantly overcome the poor solubility of chitosan at a neutral $\mathrm{pH}$, and consequently, widen its possible applicability for gene/drug delivery, tissue engineering, and wound dressing [25,26]. Therefore, quaternized chitosan (Q-Cs) derivatives are able to enhance the diffusion of drug molecules through various biological barriers in neutral/alkaline conditions [27]. These Q-Cs derivatives expose permanent positive charges that positively affect the mucoadhesivity, biocompatibility, controlled biodegradability, and drug loading/release profiles [28]. Several Q-Cs derivatives such as trimethyl-chitosan (TMC), triethyl-chitosan (TEC), dimethylethyl-chitosan (DMEC), and N-[(2-hydroxy-3-trimethylammonium) propyl] chitosan chloride (HTCC) are established as potential carriers for protein, vaccines, and anti-cancer drugs [29-32].

Herein, we aimed to combine the beneficial features of the tuned size and surface characteristics of nanocarriers, with the attractive bio-characteristics of quaternized chitosan derivatives. Thus, new nanoparticles-based quaternized aminated chitosan (Q-AmCs) derivatives were formulated for the oral delivery and slow release of Curcumin (Cur; anti-cancer drug compound), at the site of the colon. The developed nanoparticles were examined to determine their structures, thermal properties, and morphological changes through Fourier transform infrared spectroscopy (FT-IR), thermogravimetric analyzer (TGA), and transmission electron microscope (TEM). In addition, particle size and surface charges of the formulated nanoparticles were also determined. Parameters affecting the nanoparticles formation as well as Cur-drug encapsulation efficiency were optimized. Effects of the nanoparticles compositions and drug amount on the in vitro drug release profiles were also explored. Finally, biocompatibility and biodegradability of the formulated nanoparticles under the physiological environments were also evaluated.

\section{Results and Discussion}

\subsection{FT-IR Analysis}

The FT-IR spectra of the formulated nanoparticles were collected to provide additional information regarding their chemical structures, as presented in Figure 1A. It was clear that the basic characteristics of the chitosan polysaccharide structure were retained at 852$1170 \mathrm{~cm}^{-1}$. The observed characteristics included a broad band at around $3441 \mathrm{~cm}^{-1}$, in the AmCs spectrum that corresponded to the stretching vibrations of amine and hydroxyl groups [33]. These bands were shifted to 3446 and $3452 \mathrm{~cm}^{-1}$ in Q-AmCs1 and Q-AmCs2 derivatives. In addition, the bands at $1645-1649 \mathrm{~cm}^{-1}$ and $1560 \mathrm{~cm}^{-1}$ were assigned to the stretching vibration of the amide- $\mathrm{I}(\mathrm{C}=\mathrm{O}$ of $\mathrm{NH}-\mathrm{C}=\mathrm{O})$ groups and the $\mathrm{N}-\mathrm{H}$ bending of amide-II. Furthermore, the observed multiple-peaks in the wave number range of $986-$ 
$1186 \mathrm{~cm}^{-1}$ were associated with the existence of the C-C, C-O, and C-O-C glycoside bonds. The FT-IR spectra of Q-AmCs derivatives displayed characteristic absorption bands at 1855 and $1003 \mathrm{~cm}^{-1}$, which could be ascribed to the $\mathrm{C}-\mathrm{N}$ stretching vibration of the quaternary ammonium groups. Likewise, the peak intensities increased with increasing 2-chloro- $\mathrm{N}, \mathrm{N}$ diethylethylamine hydrochloride ratio (Q-AmCs2) in the reaction mixture, confirming the successful formation of the Q-AmCs. Finally, the absorption bands observed at around $1380-1400 \mathrm{~cm}^{-1}$ were assigned to the $\mathrm{C}-\mathrm{H}$ symmetric bending of the $\mathrm{CH}_{3}$ groups on the quaternary ammonium groups [34].

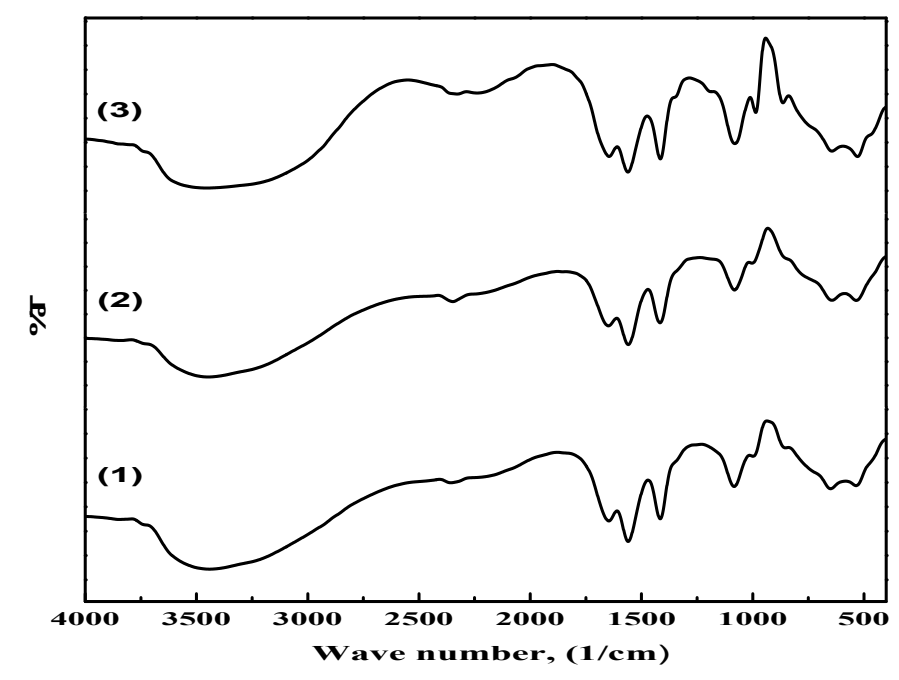

(A)

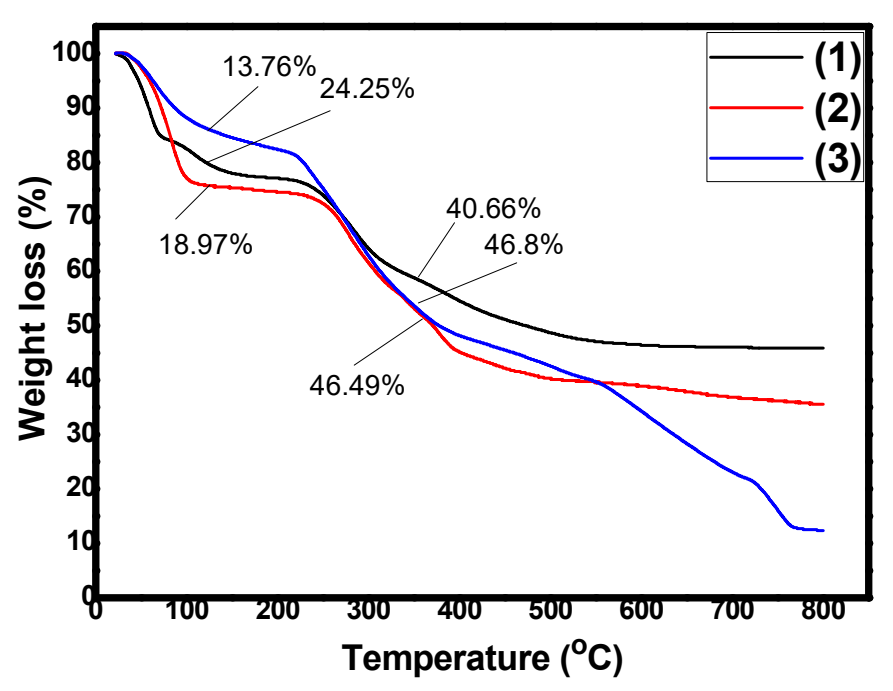

(B)

Figure 1. (A) FT-IR spectra and (B) TGA thermograms of (1) AmCs, (2) Q-AmCs1, and (3) Q-AmCs2 nanoparticles.

\subsection{Thermal Analysis}

The thermogravimetric analyzer (TGA) was applied to investigate the thermal stabilities of the AmCs and Q-AmCs nanoparticles with rising temperature, up to $800{ }^{\circ} \mathrm{C}$. Figure $1 \mathrm{~B}$ illustrates that the thermal degradation profiles for the formulated nanoparticles 
occurred in three sequential stages. The first stage was observed at the ambient temperature $\left(0-120^{\circ} \mathrm{C}\right)$, with recorded maximum weight losses of $24.25,18.97$, and $13.76 \%$ for AmCs, Q-AmCs1, and Q-AmCs2, respectively. This initial weight loss was caused by the release of the moisture content from the tested samples, including water bound by the hydrophilic groups of the nanoparticle matrix [35]. The second stage was detected at elevated temperatures up to $350{ }^{\circ} \mathrm{C}$, and was assigned to the cleavage of the $\mathrm{C}-\mathrm{O}-\mathrm{C}$ glycoside bonds and decomposition of the pyranose ring of AmCs and its quaternized forms. Finally, the third depression stage (beyond $400^{\circ} \mathrm{C}$ ) could be attributed to the thermal decomposition of adducts. These decomposition stages were consistent with the reported main thermal decomposition process of nanoparticle based-chitosan polysaccharide and its derivatives [22]. Table 1 summarizes that Q-AmCs1 and Q-AmCs2 needed temperature increases up to 370.51 and $376.9^{\circ} \mathrm{C}$, for loss of half their weights $\left(\mathrm{T}_{50}{ }^{\circ}{ }^{\circ} \mathrm{C}\right)$ compared to $475.5^{\circ} \mathrm{C}$, for the AmCs sample. It could be concluded from the obtained TGA data that the thermal stability of the AmCs nanoparticles was higher than its quaternized forms.

Table 1. TGA data for AmCs and Q-AmCs nanoparticles.

\begin{tabular}{cccc}
\hline Nanoparticles & \multicolumn{2}{c}{ Weight Loss (\%) } & $\mathbf{T}_{\mathbf{5 0} \%}{ }^{\circ} \mathbf{C}$ \\
& Ambient $\mathbf{0 - 1 2 0}{ }^{\circ} \mathbf{C}$ & Up to $\mathbf{3 5 0}{ }^{\circ} \mathbf{C}$ & \\
\hline AmCs & 24.25 & 40.66 & 475.50 \\
Q-AmCs1 & 18.97 & 46.8 & 370.51 \\
Q-AmCs2 & 13.67 & 46.49 & 376.9 \\
\hline
\end{tabular}

\subsection{Morphological Analysis}

Figure 2A,B illustrate the TEM images of the formulated AmCs and Q-AmCs nanoparticles. The images clarify that both the AmCs and its quaternized nanoparticles were well-dispersed, uniform in their size, and almost spherical in their shapes, except for a few pentagonal structures [36]. Moreover, the quaternization process slightly affected the morphology of the nanoparticles, since few large particles were noticed in the TEM image of Q-AmCs, as a result of the polarity difference between the compositions of nanoparticles (AmCs and 2-chloro- $N, N$-diethylethylamine hydrochloride).
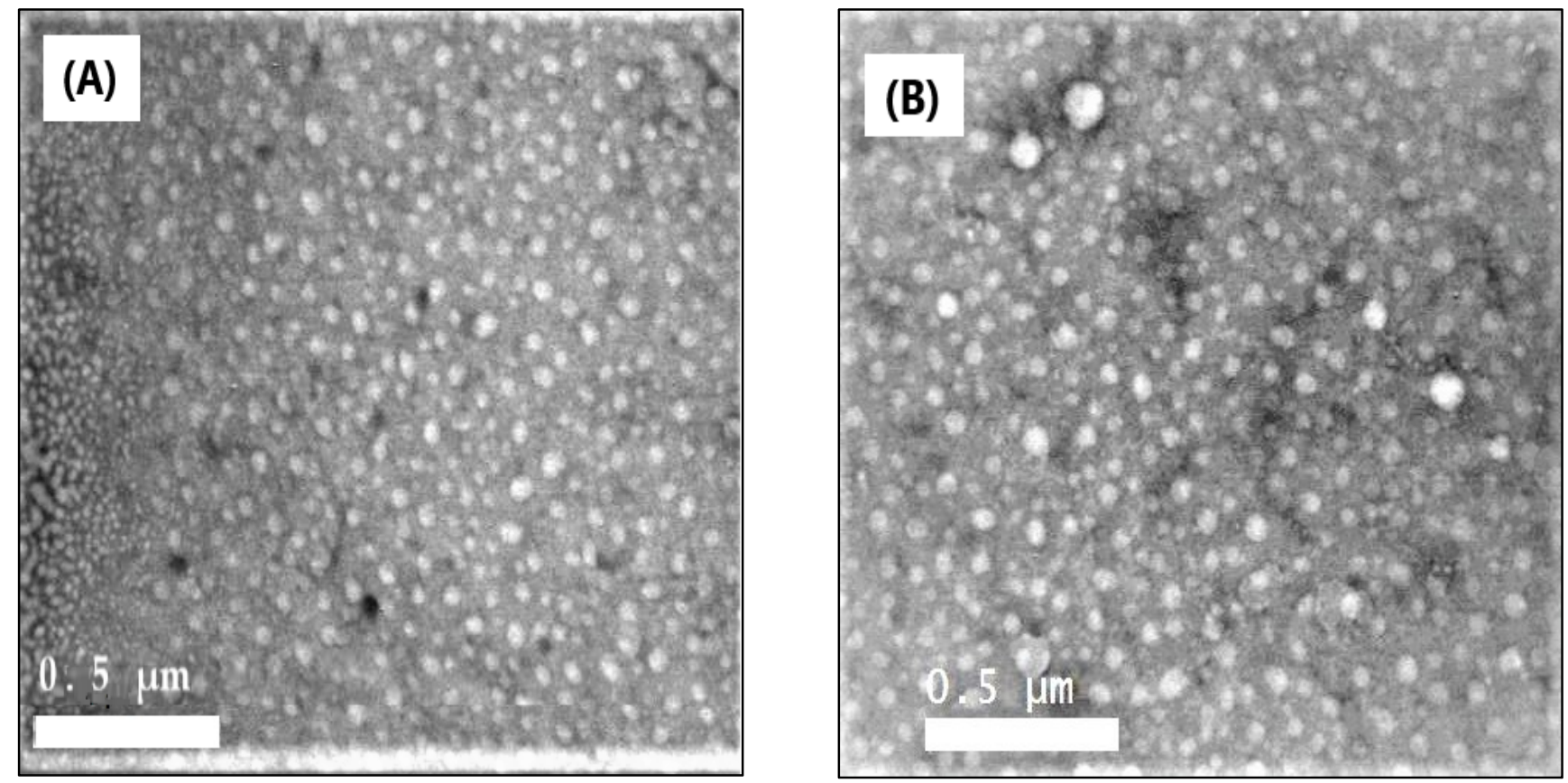

Figure 2. TEM images of (A) AmCs and (B) Q-AmCs2 nanoparticles. 


\subsection{Zeta Potentials and Particle Size Evaluation}

The zeta potential of the formulated nanoparticles was measured, as shown in Figure 3A. The results revealed that the AmCs and Q-AmCs nanoparticles had high positive charges on their entire surfaces. In addition, the Q-AmCs1 and Q-AmCs2 recorded higher values of +42.4 and $+48.3 \mathrm{mV}$, compared to $+32.8 \mathrm{mV}$ for AmCs nanoparticles. These results confirmed that quaternization of AmCs increased the positive charges on the quaternized form derivative, as a result of the formation of positively charged quaternal ammonium salts. As expected, increasing the quaternization ratio significantly augmented the zeta potential values, since more positive charges were present after formation of the nanoparticles. According to the previous studies, the nanoparticles could be present in a stable state when their surface potentials were more than $30 \mathrm{mV}$, as a result of enhancing the electrostatic repulsion forces between similar positive charges [37]. Additionally, increasing the surface positive charges promoted the electrostatic attraction forces with the negatively charged particles on the cell membrane.

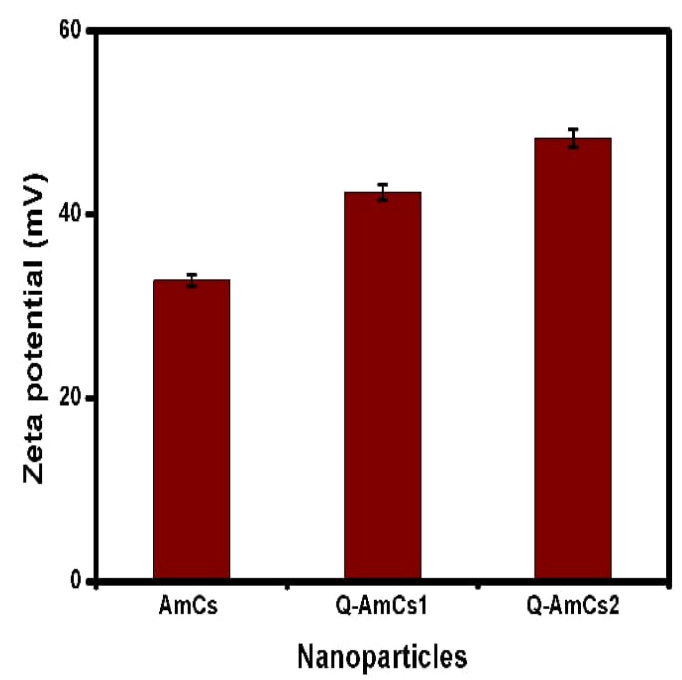

(A)

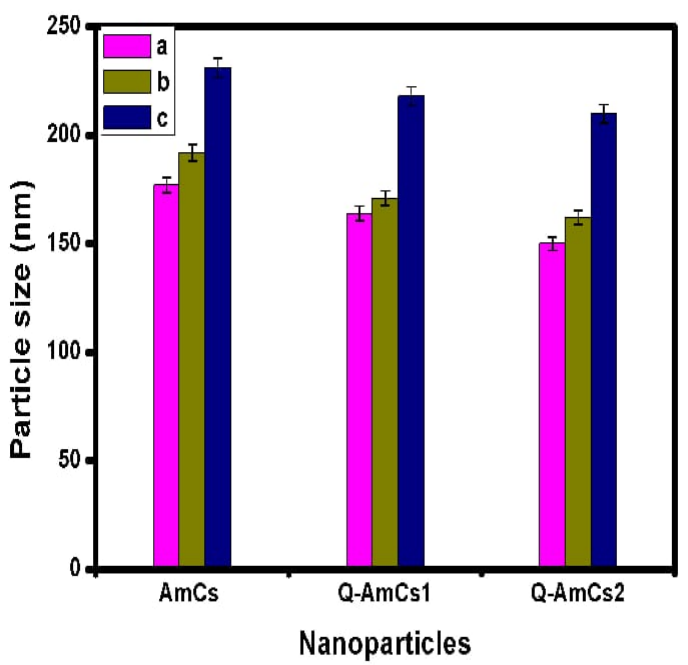

(B)

Figure 3. (A) Zeta potential and (B) particle size values of the formulated nanoparticles at different polymer/TPP ratios of (a) 5:1, (b) 10:1, and (c) 10:1.5. All measurements were performed in triplicates $(n=3)$, and values were expressed as mean + standard deviation $( \pm \mathrm{SD})$.

Additionally, at a constant polymer ratio, the increasing TPP ratio (i.e., from 10:1 to 10:1.5) resulted in an increase in the nanoparticle size, as presented in Figure 3B, with values of $231 \pm 7.14,218 \pm 4.91$, and $210 \pm 9.40 \mathrm{~nm}$ for AmCs, Q-AmCs1, and Q-AmCs2 nanoparticles, respectively. It was also observed that increasing the AmCs (or QAmCs) ratio with a constant TPP ratio (i.e., from 5:1 to 10:1) slightly increased the particle size from $177 \pm 11.24$ to $192 \pm 10.22 \mathrm{~nm}$ (for AmCs), from $164 \pm 6.54$ to $171 \pm 8.35 \mathrm{~nm}$ (for QAmCs1), and from $150 \pm 5.44$ to $162 \pm 9.10 \mathrm{~nm}$ (for Q-AmCs2) nanoparticles, respectively. These results could be rationalized, based on the hypothesis that increasing the polymer ratio led to increasing the polymer solution viscosity, which directly promoted the ionic gelation process with more adhesion. Thus, deposition of some nanoparticles took place, resulting in formation of larger nanoparticles. Moreover, increasing the TPP and AmCs (or Q-AmCs) ratios could possibly generate more electrostatic attraction forces between the negatively charged TPP and the polycation polymer (AmCs and Q-AmCs), and thus, the particle size increased consequently. The results denoted that the quaternized AmCs nanoparticles displayed smaller particle size $(150 \pm 5.44-218 \pm 4.91 \mathrm{~nm})$ compared to the native AmCs nanoparticles (177 $\pm 11.24-231 \pm 7.14 \mathrm{~nm})$, and the size decreased with rising quaternization ratio in the nanoparticles matrix. This behavior was noticed for all tested 
polymer/TPP ratios. It was stated that the effective particle size for the injectable drug nanocarriers was mostly below $200 \mathrm{~nm}[38,39]$. These sizes were met by our results for all formulated nanoparticles, with polymer/TPP ratios of 5:1 and 10:1, and thus, they were selected for the subsequent encapsulation studies.

\subsection{Cur-Drug Loading Evaluation}

Considerable loading efficiency was required to attain the anticipated therapeutic impact of the drug dose, without hampering its biological action. Herein, the Curcumin-drug was successfully loaded into the formulated nanoparticles, with the encapsulation efficiency shown in Figure 4 . At a constant Cur-drug amount $(20 \mathrm{mg})$, the Cur-encapsulation efficiency was greatly improved after the quaternization process, with the highest value of $94.4 \pm 0.91 \%$ recorded using the Q-AmCs2 nanoparticles, compared to $75 \pm 1.13 \%$ for AmCs nanoparticles. In addition, a slight decrease in the encapsulation efficiency value was noticed when increasing the polymer/TPP ratio from 5:1 to 10:1 (Figure 4A). These results were consistent with improving the positively charged surface of nanoparticles with the increasing quaternization ratio, and agreed with the zeta potential measurements. Thus, more Cur-drug molecules were able to bind with the positive Q-AmCs surface via several interactions, comprising hydrogen bonding and the electrostatic attractions between the opposite charges [40]. This in turn led to enhancing the encapsulation efficiency values. In contrast, raising the polymer ratio (AmCs or Q-AmCs) at a constant TPP ratio (i.e., 10:1) would produce a viscous solution that adversely affected the dispersion of drug molecules through the polymer matrix, resulting in a slight decrease in the encapsulation efficiency.

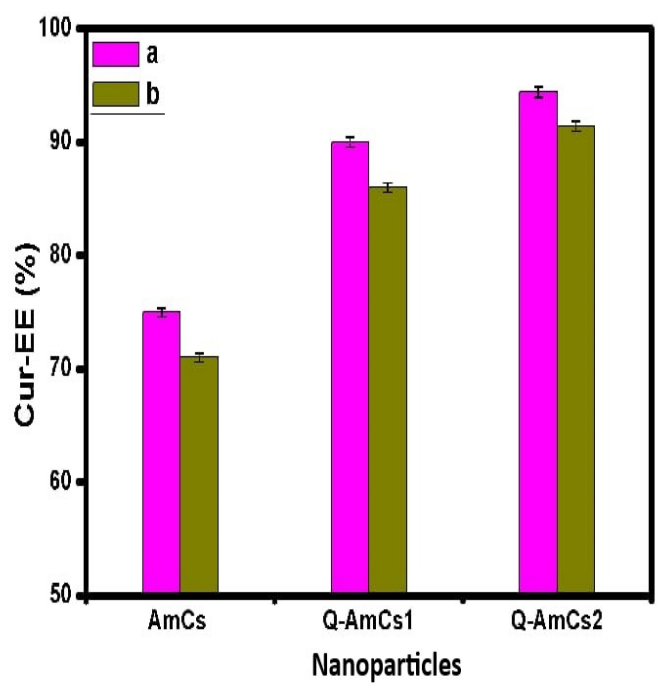

(A)

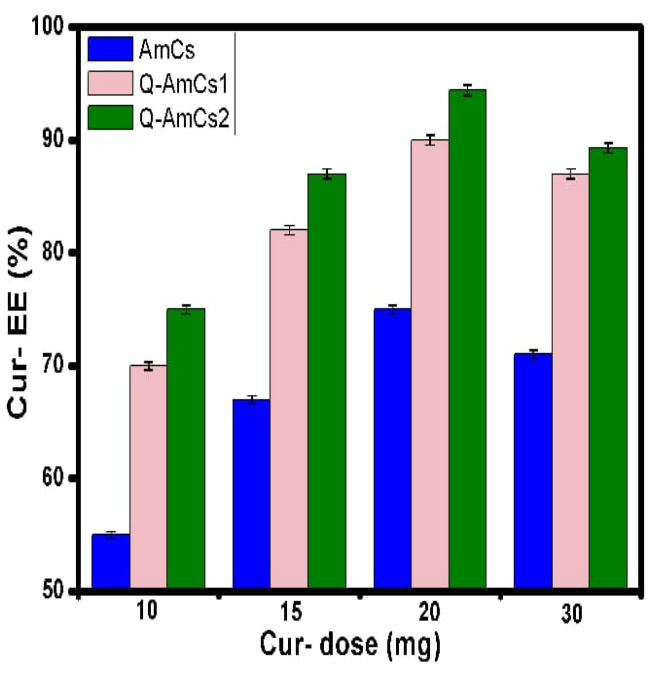

(B)

Figure 4. Encapsulation efficiency (EE\%) values of the Cur-loaded NPs at (A) different polymer/TPP ratios [(a) 5:1and (b) 10:1], and (B) at different initial Cur-dose. All measurements were performed in triplicates $(n=3)$, and the values were expressed as mean + standard deviation $( \pm \mathrm{SD})$.

Figure 4B illustrates that as the initial Cur-dose increased, the encapsulation efficiency increased in general. For all tested nanoparticles, the Cur-EE\% values were greatly augmented with increasing the dose from 10 to $20 \mathrm{mg}$. These results could be related to increasing the probabilities of more Cur-drug molecules to be encapsulated by the formulated nanoparticles. However, upon further increase in the Cur-drug dose up to $30 \mathrm{mg}$, the Cur-EE\% decreased from $75 \pm 1.13$ to $71 \pm 0.743 \%$ (for AmCs NPs), from $90 \pm 0.62$ to $87 \pm 0.61 \%$ (for Q-AmCs1 NPs), and from $94.4 \pm 0.91$ to $89.3 \pm 0.55 \%$ (for Q-AmCs2 NPs), respectively. This reduction could be a result of the limited capacity of the nanoparticles, which might have reached the saturation state, by using $20 \mathrm{mg}$ of Cur-drug. The higher 
initial drug dose $(30 \mathrm{mg}$ ) could hinder the passage as well as obstruct the proper dispersion of Cur-molecules through the polymer matrix. Thus, some of drug molecules were not encapsulated, and they mostly leached through the formulation process.

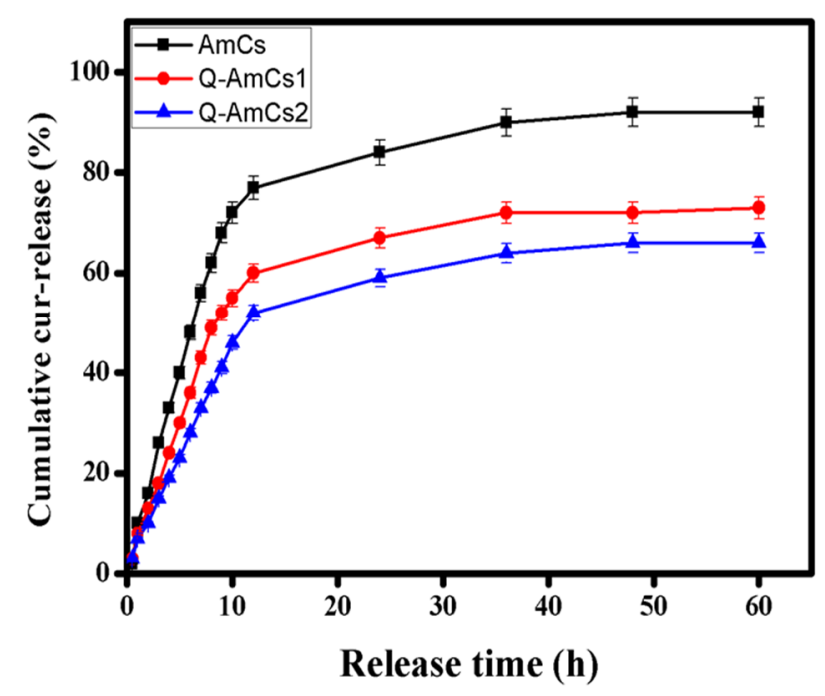

(A)

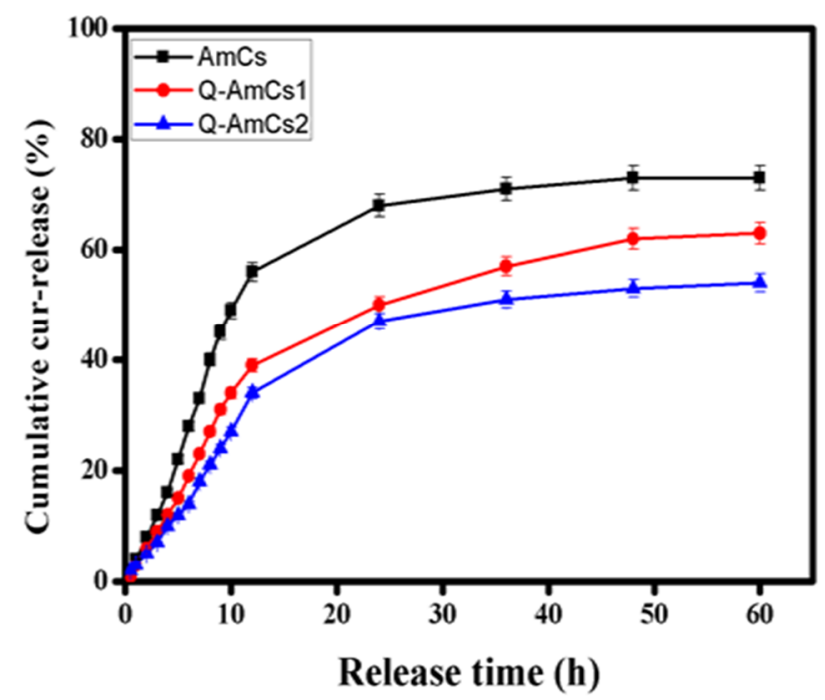

(B)

Figure 5. Cumulative Cur-release profiles of the formulated Cur-loaded NPs at (A) SGF (pH 1.2) and (B) SCF (pH 7.4). All measurements were performed in triplicates $(n=3)$, and the values were expressed as mean + standard deviation $( \pm \mathrm{SD})$.

\subsection{In Vitro Cur-Drug Release Evaluation}

The release profiles of Cur-drug were investigated under simulated gastrointestinal conditions, and the results are depicted in Figure 5A,B. The results showed a rapid Currelease from all tested nanoparticles at the initial release stage. It was observed that after $12 \mathrm{~h}$ from the initial release time, the maximum cumulative release values were recorded for AmCs, Q-AmCs1, and Q-AmCs2, respectively, as-77.0, 60.0, and $52.0 \%$ at $\mathrm{pH} 1.2$, and $56.0,39.0$, and $34.0 \%$, at $\mathrm{pH}$ 7.4. Subsequently, a slow release rate was noticed with the prolongation of the Cur-release time for all formulations. For the Cur-loaded Q-AmCs $\mathrm{NPs}$, the in vitro Cur-release rate was greatly decreased at $\mathrm{pH} 1.2$ [SGF] and $\mathrm{pH} 7.4$ [SCF], compared to that of Cur-loaded AmCs NPs. The results also showed that increasing the 
quaternization ratio in the Q-AmCs NPs led to a further decrease in the Cur-release values. After $60 \mathrm{~h}$, the cumulative Cur-release values at $\mathrm{pH} 1.2$ were decreased from 73.0\% (QAmCs1) to $66.0 \%$ (Q-AmCs2), and from 63.0\% (Q-AmCs1) to 54.0\% (Q-AmCs2) at pH 7.4. Cur-loaded AmCs NPs recorded the highest cumulative release values of 92.0 and $73.0 \%$ at pH 1.2 and pH 7.4, respectively. Similar results were obtained by Sun et al. [41]. They reported that a sustained Curcumin release took place from the nanoparticles based on the Ion-Crosslinking Aminochitosan-modified folic acid (FA). The cumulative release (\%) of Curcumin reached a maximum value of $56.2 \%$ after $48 \mathrm{~h}$, compared to $54 \%$ after $60 \mathrm{~h}$ in the present study. Hasan et al. observed that the Curcumin release was much lower in the case of chitosan-coated nanoliposomes compared to the uncoated nanoliposomes [42]. Additionally, Nasab et al. indicated that the existence of chitosan shell on the surface of mesoporous silica nanocarriers greatly improved the slow and sustained release rate of Curcumin at a low $\mathrm{pH}$, compared to the environment $\mathrm{pH}$ [43].

In fact, most of the $\mathrm{NH}_{2}$ groups of AmCs NPs were consumed through the ionic crosslinking with TPP for the formation of nanoparticles, while the remaining free groups would be protonated at $\mathrm{pH} 1.2$ and transformed into positively charged $\mathrm{NH}_{3}{ }^{+}$groups. These positive charges could easily interact with the negative charges of the Cur-drug via electrostatic attraction forces, resulting in a decrease in the cumulative release rate. Furthermore, the introduced quaternary ammonium groups provide permanent positive charges in the Q-AmCs NPs, as verified by the zeta potential measurements. This would directly generate very strong electrostatic interactions with the Cur-drug, which would further prevent its rapid release, and thus, an additional decline for the cumulative release rate took place. These results presented in Figure 5 were in the agreement with other reported studies $[25,44]$.

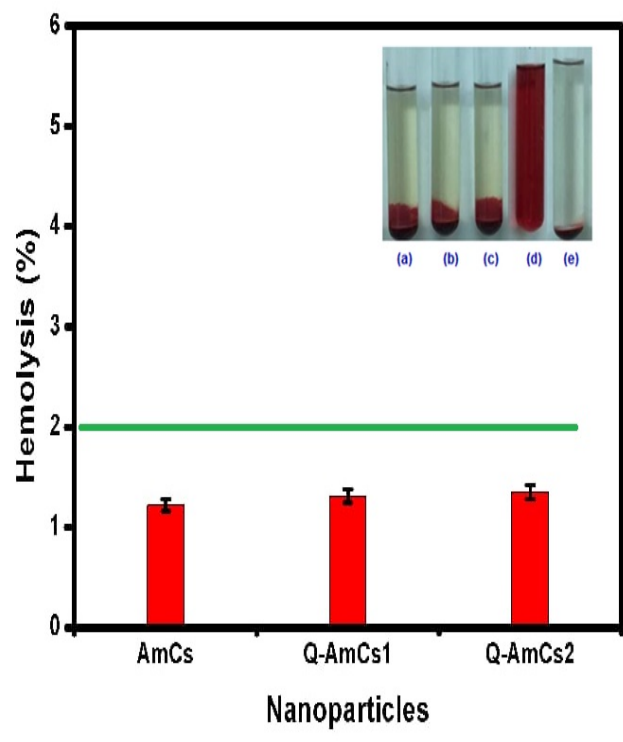

(A)

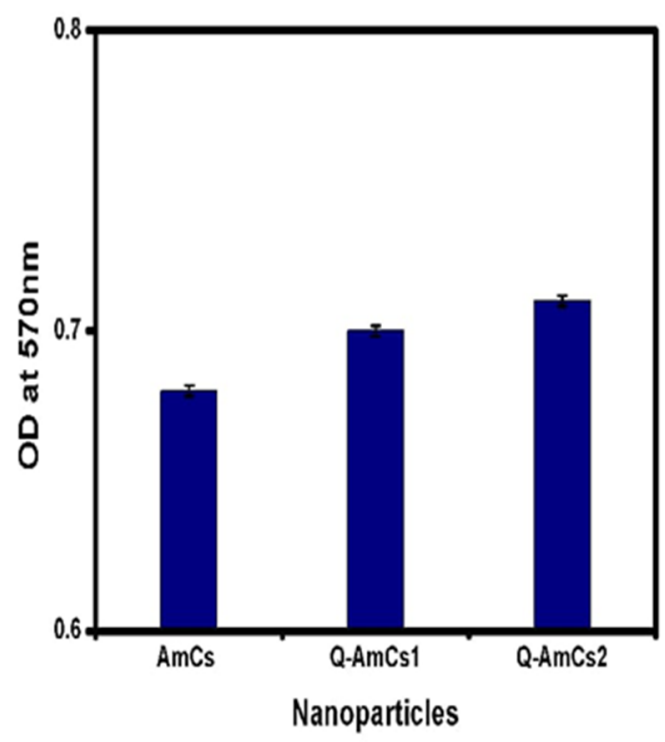

(B)

Figure 6. (A) Hemocomptibility data and blood-containing tubes images of (a) AmCs NPs, (b) Q-AmCs1 NPs, (c) Q-AmCs2 NPs, (d) positive control, and (e) negative control) nanoparticles. (B) Biodegradation profiles of AmCs, Q-AmCs1, and QAmCs2 NPs shown by the formation of DNS adduct with liberated sugars, after incubation of NPs (10 mg) with lysozyme for 3 days, at $37^{\circ} \mathrm{C}$. All measurements were performed in triplicates $(n=3)$, and the values were expressed as mean + standard deviation $( \pm \mathrm{SD})$.

\subsection{Biocompatibility and Biodegradability Evaluation}

According to the standard protocol for testing the hemolytic properties of materials (ASTM F756-00), biomaterials could be characterized as hemolytic materials (hemolytic 
index over $5 \%$ ), slightly hemolytic materials (hemolytic index in the range of $2-5 \%$ ), and non-hemolytic materials (hemolytic index in the range of 0-2\%) [45]. Figure 6A displayed the blood-containing tube images and data of hemocompatibility for the formulated nanoparticles, which was evaluated as a function of the blood-hemolysis percent. The data demonstrated that the as-formulated AmCs and Q-AmCs nanoparticles showed little hemolysis. The good hemocompatibility could be attributed to the excellent biocompatibility nature of chitosan biopolymer. Figure $6 \mathrm{~B}$ represents the biodegradation profiles of the developed nanocarriers, measured by incubating the lysozyme solution. The glycosidic bonds could be hydrolyzed by the lysozyme enzyme, resulting in a biodegradation of the polysaccharide structure. This enzymatic activity might be enhanced by the hydrophilic groups in the nanoparticles matrix, which would potentially allow for adsorption of enzyme. The results showed that all tested samples were biodegraded by the lysozyme enzyme, due to their core construction [46,47].

\section{Materials and Methods}

\subsection{Materials}

Chitin from shrimp shells ( $>95 \%$ acetylated), 2-chloro- $N, N$-diethylethylamine hydrochloride (assay 99\%), Curcumin (Cur; $\geq 94 \%$ curcuminoid content), ethylenediamine (EDA; assay $\geq 99 \%$ ), $N$-methyl-2-pyrrolidinone (NMP; purity $98 \%$ ), sodium tripolyphosphate (TPP; assay $85 \%$ ), sodium iodide (NaI; assay $\geq 99 \%$ ), and para-benzoquinone (PBQ; assay $\geq 94 \%$ ) were purchased from Sigma-Aldrich Chemie $\mathrm{GmbH}$ (Taufkirchen, Germany). Sodium hydroxide (pellets; assay 98\%), acetic acid (purity 98\%), acetone (assay 99\%), and ethanol (assay 99\%) were delivered by El-Nasr Pharmaceutical Co. (Cairo, Egypt). All chemicals and solvent were of analytical grade and were used without further purification.

\subsection{Synthesis of AmCs Derivative}

The aminated chitosan derivative was prepared and purified according to the authors previous work [21,48]. In brief, an accurate amount of chitin $(8 \mathrm{~g})$ was dispersed in the PBQ $(6.9 \mathrm{mM} ; 100 \mathrm{~mL})$ solution, under gentle stirring. The reaction was conducted at room temperature for $6 \mathrm{~h}$, while the $\mathrm{pH}$ of the mixture was raised to 10 using the $\mathrm{NaOH}(0.1$ $\mathrm{mol} / \mathrm{L}$ ) solution. Then, the mixture content was filtered and washed with distilled water to eliminate the unreacted PBQ molecules. The resultant activated chitin was then soaked at room temperature, in a solution of EDA $(1.8 \mathrm{mM} ; 100 \mathrm{~mL})$ for further $6 \mathrm{~h}$, to ensure the complete amination step. The produced aminated chitin was separated and washed several times by distilled water, to remove the excess EDA molecules. Finally, the resultant aminated chitin was immersed in $\mathrm{NaOH}(50 \%)$ under a reflux conditions $\left(12 \mathrm{~h} ; 120^{\circ} \mathrm{C}\right)$ to complete the deacetylation process. The obtained aminated chitosan (AmCs) was separated from the reaction medium and followed by filtration, washing until neutrality and drying in a vacuum oven at $60^{\circ} \mathrm{C}$.

\subsection{Synthesis of $Q-A m C s$ Derivative}

Quaternization of AmCs derivative was achieved according to the reported reductive alkylation method [49], with a slight modification. In a 2-necked flask, AmCs (1 g) and sodium iodide (4.8 g; as a catalyst) were dissolved in $80 \mathrm{~mL}$ of $\mathrm{N}$-methyl-2-pyrrolidinone/ acetic acid (1\%), using shaking water bath at $60{ }^{\circ} \mathrm{C}$, until it reached complete dissolution of AmCs. Next, the flask was connected to a condensation column, followed by the addition of excess of 2-Chlorotriethylamine hydrochloride solution under continuous stirring, while $\mathrm{NaOH}(15 \%(w / v) ; 11 \mathrm{~mL})$ was added dropwise during the reaction process. The product was then precipitated using $200 \mathrm{~mL}$ of ethanol, centrifuged, washed by acetone, and finally dried under reduced pressure. Two ratios of 2-chloro, $\mathrm{N}, \mathrm{N}$-diethylethylamine hydrochloride were used per 1 mole of AmCs and coded as: (Q-AmCs1 [1:0.534 M], and Q-AmCs2 [1:1.602 M]. The proposed reaction mechanism for the preparation of AmCs and Q-AmCs derivatives is presented in Figure 7. 


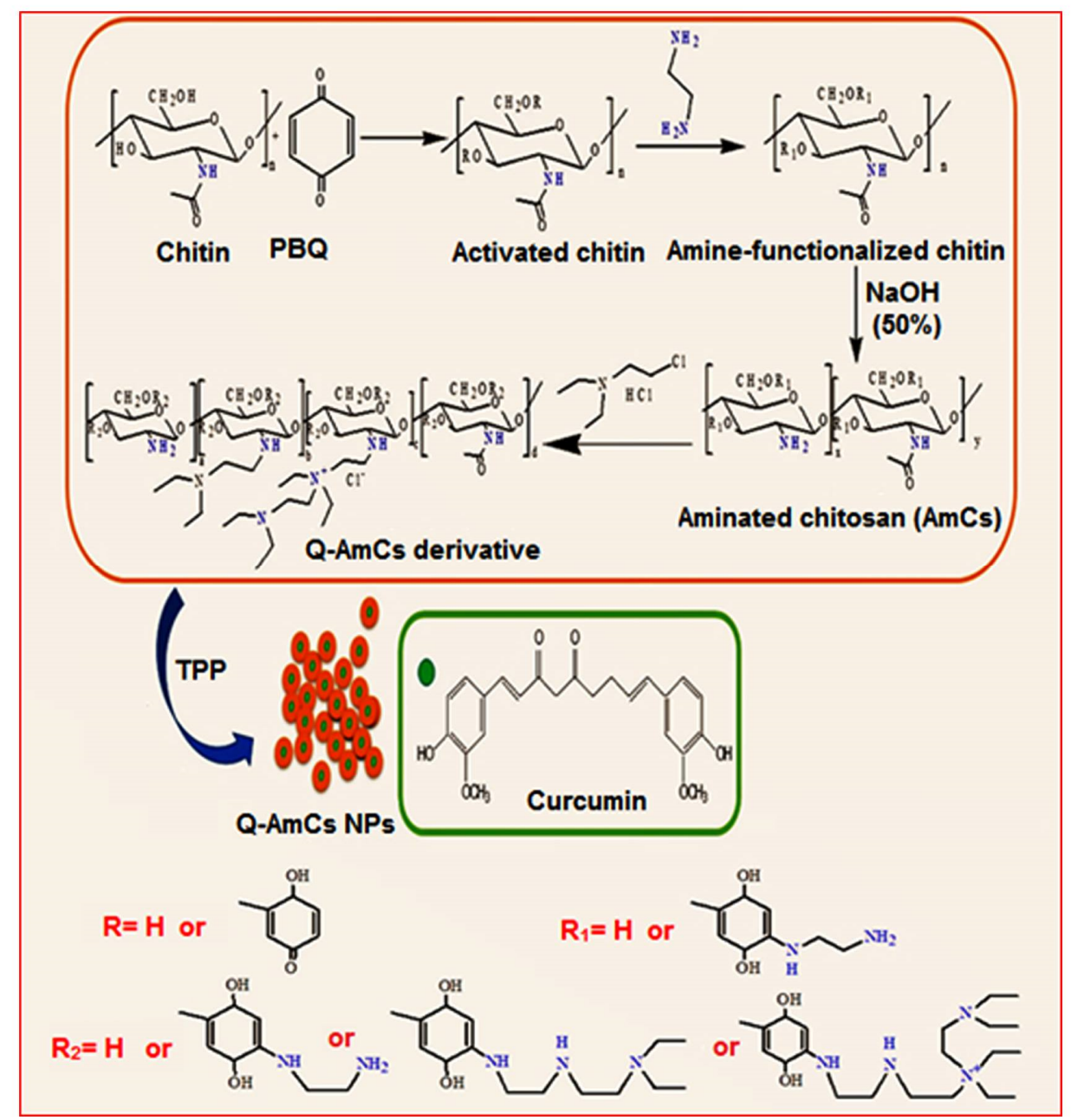

Figure 7. A schematic diagram for the synthesis of quaternized aminated chitosan (Q-AmCs) derivative.

\subsection{Formulation of $Q-A m C s N P S$}

Q-AmCs NPs were formulated according to the ionic gelation technique, using TPP as an ionic crosslinker [31]. First, an exact quantity of the Q-AmCs powder was dissolved at room temperature in de-ionized water, with a final concentration of $(0.2 \% ; w / v)$. Next, the TPP solution $(0.1 \% ; w / v)$ was dropped slowly into the prepared Q-AmCs solution via a peristaltic pump, under high stirring speed at room temperature. After $20 \mathrm{~min}$, the formed nanoparticles were separated from the gelling medium through centrifugation of the dispersion at 12,000 rpm for $20 \mathrm{~min}$. The collected nanoparticles were freeze-dried overnight and followed by sortation at $4{ }^{\circ} \mathrm{C}$. Three ratios of Q-AmCs/TPP were used as 5:1, 10:1, and 10:1.5. Additionally, the same steps were applied for the formulation of AmCs nanoparticles, except for dissolving AmCs $(0.2 \% ; w / v)$ in acetic acid $(1 \% ; w / v)$ instead of the de-ionized water.

\subsection{Cur-Drug Loading Step}

To encapsulate the Cur-drug into the developed Q-AmCs NPs, a precise amount of Cur-drug (10-30 mg) was dissolved in $5 \mathrm{~mL}$ of ethanol, and subsequently added to the previously prepared AmCs and Q-AmCs solutions, with continuous stirring for $30 \mathrm{~min}$ at room temperature, to obtain homogenous mixtures. The same procedure described above (Section 3.4) was followed to obtain Cur-loaded Q-AmCs nanoparticles. In order to assess the Cur-encapsulation efficiency (Cur-EE (\%)), the freeze-dried Cur-loaded Q-AmCs NPs were re-suspended in ethanol, twisted using Vortex, and centrifuged. By using a UV-spectrophotometer, the leached amount of Cur-drug from nanoparticles was estimated 
at $429 \mathrm{~nm}$ [44], and the Cur-EE (\%) was calculated according to Equation (1). The filtrate solution of free drug-nanoparticle was used as a control reference.

$$
\text { Cur }-\mathrm{EE}(\%)=\frac{W_{i}-W_{f}}{W_{i}} \times 100
$$

where $W_{i}$ represents the initial quantity of the Cur-drug added to the Q-AmCs solution, and $W_{f}$ is the final quantity of Cur-drug per weighted amount of the loaded NPs.

\subsection{Physicochemical Characterization}

The functional groups of the developed nanoparticles were determined by Fourier transform infrared spectroscopy (FT-IR, Model 8400 S, Shimadzu, Kyoto, Japan) and thermal examination was done by Thermogravimetric analyzer (TGA, Model 50/50H, Shimadzu). The morphological changes were investigated by a Transmission electron microscope (TEM, JEM-100CX, JEOL INC., Peabody, Kansas, USA). The average sizes of the formulated nanoparticles were estimated by a Particle size analyzer (Beckman, Coulter N5, Brea, CA., USA). Additionally, determination of the surface charges was achieved by the Zeta-Sizer (Malvern Panalytical Co., Royston, UK).

\subsection{In Vitro Cur-Drug Release Study}

The formulated Cur-loaded nanoparticles were examined for the Cur-drug release efficiency under simulated intestinal conditions. Herein, a definite amount of tested samples was re-dispersed in separate aqueous solutions of saline phosphate buffer $(\mathrm{pH}$ 7.4; $10 \mathrm{~mL}$ ) as a simulated colon fluid [SCF], and $\mathrm{HCl}(\mathrm{pH} 1.2 ; 10 \mathrm{~mL})$ as a simulated gastric fluid [SGF]. The in vitro release process was performed by a dissolutor instrument under constant conditions $\left(50 \mathrm{rpm}, 37^{\circ} \mathrm{C}\right.$ ). After time intervals, $1 \mathrm{~mL}$ of the release medium was collected for assaying; while an equivalent volume of the freshly prepared buffer was added to the release medium. The cumulative Cur-release percentage was measured by a UV-spectrophotometer at $429 \mathrm{~nm}$.

\subsection{Biocompatibility Test}

Biocompatibility of the formulated nanoparticles was investigated according to the previously reported method, with a minor modification [45]. A known amount of freezedried nanoparticles $(10 \mathrm{mg}$ ) was first washed using a fresh phosphate buffer ( $\mathrm{pH}$ 7.4) solution for $72 \mathrm{~h}$. Next, the tested samples were rinsed and soaked in a glass test tube containing an ACD-blood mixture, which was previously prepared by mixing fresh human blood $(9 \mathrm{~mL})$ with acid citrate dextrose $(1 \mathrm{~mL}$; as anti-coagulant). For blood tests, informed consent was obtained from a volunteer before the use of his blood and the examinations were carried out in compliance with relevant guidelines. The mixtures were maintained at $37^{\circ} \mathrm{C}$ for $3 \mathrm{~h}$, followed by centrifugation for $15 \mathrm{~min}$ at 20,000 rpm. A control was performed using a free-sample mixture, while phosphate buffer and water were used as negative and positive controls, respectively. The supernatants were examined via estimation of the optical density (OD) at $540 \mathrm{~nm}$, using a UV-spectrophotometer, and their hemolysis percent was calculated according to the following equation:

$$
\text { Hemolysis }(\%)=\frac{(\text { ODsample }- \text { ODnegative control })}{(\text { ODpositive control }- \text { ODnegative control })} \times 100
$$

\subsection{In Vitro Biodegradability Test}

Biodegradability of the formulated nanoparticles was examined according to the previously published method [50]. A known quantity of tested nanoparticles $(10 \mathrm{mg})$ was soaked for 3 days at $37^{\circ} \mathrm{C}$, in a tube containing a mixture of phosphate buffer $(2 \mathrm{~mL}$; $\mathrm{pH} 7.0)$ and lysozyme solution $(0.5 \mathrm{~mL})$. The activity of lysozyme was stopped by the addition of 3,5-dinitrosalicylic acid (DNS; $1.5 \mathrm{~mL}$ ) used as a reagent for the estimation of reduced sugar from the nanoparticle matrix. Subsequently, the mixture was transferred 
into a water bath, left for boiling at $100{ }^{\circ} \mathrm{C}$ for $15 \mathrm{~min}$, and followed by cooling at room temperature. The produced color from the reaction of the reduced liberated sugar from nanoparticles, with the DNS-reagent, was analyzed by measuring the optical density (OD) at a wavelength of $570 \mathrm{~nm}$ using a visible-spectrophotometer.

All experiments were performed in triplicates $(n=3)$, and the gained data were expressed as the mean + standard deviation $( \pm$ S.D.)

\section{Conclusions}

In this study, quaternized aminated chitosan nanoparticles were formulated and characterized. The developed nanoparticles showed acceptable particle size (162 $\pm 9.10 \mathrm{~nm})$ and a higher surface potential $(+48.3 \mathrm{mV})$ compared to the unmodified AmCs. The results signified that Q-AmCs NPs could encapsulate $94.4 \pm 0.91 \%$ of the Cur-drug (20 mg), as compared to $75.0 \pm 1.13 \%$ in the AmCs NPs. The release studies confirmed that the Cur-release rate was decreased at $\mathrm{pH} 7.4$ [SCF], with an increasing quaternization ratio, and recorded a maximum value of $54 \%$, after $60 \mathrm{~h}$ of the initial release time. Bioevaluation studies clarified that the formulated NPs were biocompatible (non-hemolytic) and biodegradable, under the physiological conditions. Therefore, the Q-AmCs NPs could be potentially used for the delivery and slow release of anticancer drugs.

Author Contributions: Conceptualization, A.M.O.; methodology, A.M.O.; Project administrator, A.M.O.; formal analysis, A.M.O., T.M.T., and M.A.H.; writing-original draft preparation, A.M.O.; review and editing A.M.O., R.E.K., M.S.M.-E., Z.M.Z., and M.A.T.B.; supervision, A.M.O., Z.M.Z., and M.A.T.B. All authors have read and agreed to the published version of the manuscript.

Funding: This research was funded by the Science and Technology Development Fund (STDF), grant number 25398, and the APC was partially funded by STDF and the City of Scientific Research and Technological Applications (SRTA-City).

Data Availability Statement: The data presented in this study are available on request from the corresponding author.

Acknowledgments: This paper is based on work supported by Science and Technology Development Fund (STDF) under the capacity building grant (STDF-STF), grant number 25398. The authors are thankful to the Institute for Molecular Bioscience at the University of Queensland, Australia, for providing laboratory facilities.

Conflicts of Interest: The authors declare no conflict of interest.

Sample Availability: Samples of the compounds are available from the authors.

\section{References}

1. Bae, Y.H.; Park, K. Advanced drug delivery 2020 and beyond: Perspectives on the future. Adv. Drug Deliv. Rev. 2020, 158, 4-16. [CrossRef] [PubMed]

2. Wei, Q.Y.; Xu, Y.M.; Lau, A.T.Y. Recent Progress of Nanocarrier-Based Therapy for Solid Malignancies. Cancers 2020, 12, 2783. [CrossRef] [PubMed]

3. Sung, Y.K.; Kim, S.W. Recent advances in polymeric drug delivery systems. Biomater. Res. 2020, 24, 1-12. [CrossRef] [PubMed]

4. Sun, X.; Wang, N.; Yang, L.-Y.; Ouyang, X.-K.; Huang, F. Folic acid and PEI modified mesoporous silica for targeted delivery of curcumin. Pharmaceutics 2019, 11, 430. [CrossRef] [PubMed]

5. Patra, J.K.; Das, G.; Fraceto, L.F.; Campos, E.V.R.; del Pilar Rodriguez-Torres, M.; Acosta-Torres, L.S.; Diaz-Torres, L.A.; Grillo, R.; Swamy, M.K.; Sharma, S. Nano based drug delivery systems: Recent developments and future prospects. J. Nanobiotechnol. 2018, 16, 71. [CrossRef] [PubMed]

6. Lombardo, D.; Kiselev, M.A.; Caccamo, M.T. Smart nanoparticles for drug delivery application: Development of versatile nanocarrier platforms in biotechnology and nanomedicine. J. Nanomater. 2019, 12, 1-26. [CrossRef]

7. Siddique, S.; Chow, J.C.L. Application of Nanomaterials in Biomedical Imaging and Cancer Therapy. Nanomaterials 2020, 10, 1700. [CrossRef]

8. Siddique, S.; Chow, J.C.L. Gold Nanoparticles for Drug Delivery and Cancer Therapy. Appl. Sci. 2020, 10, 3824. [CrossRef]

9. Dunuweera, S.P.; Rajapakse, R.M.S.I.; Rajapakshe, R.B.S.D.; Wijekoon, S.H.D.P.; Nirodha Thilakarathna, M.G.G.S.; Rajapakse, R.M. Review on Targeted Drug Delivery Carriers Used in Nanobiomedical Applications. Curr. Nanosci. 2019, 15, 382-397. [CrossRef]

10. Naqvi, S.; Panghal, A.; Flora, S. Nanotechnology: A promising approach for delivery of neuroprotective drugs. Front. Neurosci. 2020, 14, 494. [CrossRef] [PubMed] 
11. Yaneva, Z.; Ivanova, D.; Nikolova, N.; Tzanova, M. The 21st century revival of chitosan in service to bio-organic chemistry. Biotechnol. Biotechnol. Equip. 2020, 34, 221-237. [CrossRef]

12. Naseri-Nosar, M.; Ziora, Z.M. Wound dressings from naturally-occurring polymers: A review on homopolysaccharide-based composites. Carbohydr. Polym. 2018, 189, 379-398. [CrossRef] [PubMed]

13. Tamer, T.M.; Hassan, M.A.; Valachová, K.; Omer, A.M.; El-Shafeey, M.E.A.; Mohy-Eldin, M.S.; Šoltés, L. Enhancement of wound healing by chitosan/hyaluronan polyelectrolyte membrane loaded with glutathione: In vitro and in vivo evaluations. J. Biotechnol. 2020, 310, 103-113. [CrossRef] [PubMed]

14. Sun, X.; Liu, C.; Omer, A.; Lu, W.; Zhang, S.; Jiang, X.; Wu, H.; Yu, D.; Ouyang, X.-K. pH-sensitive ZnO/carboxymethyl cellulose/chitosan bio-nanocomposite beads for colon-specific release of 5-fluorouracil. Int. J. Biol. Macromol. 2019, 128, 468-479. [CrossRef] [PubMed]

15. Gan, Q.; Wang, T.; Cochrane, C.; McCarron, P. Modulation of surface charge, particle size and morphological properties of chitosan-TPP nanoparticles intended for gene delivery. Colloids Surf. B Biointerfaces 2005, 44, 65-73. [CrossRef] [PubMed]

16. De Campos, A.M.; Sánchez, A.; Alonso, M.A.J. Chitosan nanoparticles: A new vehicle for the improvement of the delivery of drugs to the ocular surface. Appl. Cyclosporin A Int. J. Pharm. 2001, 224, 159-168.

17. Dellali, K.Z.; Rata, D.M.; Popa, M.; Ouagued, A.; Gherghel, D. Antitumoral Drug: Loaded Hybrid Nanocapsules Based on Chitosan with Potential Effects in Breast Cancer Therapy. Int. J. Mol. Sci. 2020, 21, 5659. [CrossRef] [PubMed]

18. El-Sayed, E.M.; Tamer, T.M.; Omer, A.M.; Mohy Eldin, M.S. Development of novel chitosan schiff base derivatives for cationic dye removal: Methyl orange model. Desalination Water Treat. 2016, 57, 22632-22645. [CrossRef]

19. Pokhrel, S.; Yadav, P.N. Functionalization of chitosan polymer and their applications. J. Macromol. Sci. A 2019, 56, 450-475. [CrossRef]

20. Yu, S.; Hao, S.; Sun, B.; Zhao, D.; Yan, X.; Jin, Z.; Zhao, K. Quaternized chitosan nanoparticles in vaccine applications. Curr. Med. Chem. 2020, 27, 4932-4944. [CrossRef]

21. Tamer, T.M.; Hassan, M.A.; Omer, A.M.; Valachová, K.; Eldin, M.S.M.; Collins, M.N.; Šoltés, L. Antibacterial and antioxidative activity of O-amine functionalized chitosan. Carbohydr. Polym. 2017, 169, 441-450. [CrossRef] [PubMed]

22. Mohy Eldin, M.; Soliman, E.; Hashem, A.; Tamer, T. Antimicrobial activity of novel aminated chitosan derivatives for biomedical applications. Adv. Polym. Technol. 2012, 31, 414-428. [CrossRef]

23. Omer, A.; Tamer, T.; Hassan, M.; Rychter, P.; Eldin, M.M.; Koseva, N. Development of amphoteric alginate/aminated chitosan coated microbeads for oral protein delivery. Int. J. Biol. Macromol. 2016, 92, 362-370. [CrossRef] [PubMed]

24. Wang, C.; Fu, X.; Yang, L. Water-soluble chitosan nanoparticles as a novel carrier system for protein delivery. Chin. Sci. Bull. 2007, 52, 883-889. [CrossRef]

25. Wen, Y.; Zhang, X.Y.; Sheng, L.; Lian, X.J. Preparation and in vitro Release Study of Quaternized Chitosan Nanoparticles. Adv. Mater. Res. 2014, 1053, 466-472. [CrossRef]

26. De Britto, D.; Celi Goy, R.; Campana Filho, S.P.; Assis, O.B. Quaternary salts of chitosan: History, antimicrobial features, and prospects. Int. J. Carbohydr. Chem. 2011, 2011, 312539. [CrossRef]

27. Fabiano, A.; Beconcini, D.; Migone, C.; Piras, A.M.; Zambito, Y. Quaternary Ammonium Chitosans: The Importance of the Positive Fixed Charge of the Drug Delivery Systems. Int. J. Mol. Sci. 2020, 21, 6617. [CrossRef]

28. Sadeghi, A.M.; Dorkoosh, F.; Avadi, M.; Weinhold, M.; Bayat, A.; Delie, F.; Gurny, R.; Larijani, B.; Rafiee-Tehrani, M.; Junginger, $\mathrm{H}$. Permeation enhancer effect of chitosan and chitosan derivatives: Comparison of formulations as soluble polymers and nanoparticulate systems on insulin absorption in Caco-2 cells. Eur. J. Pharm. Biopharm. 2008, 70, 270-278. [CrossRef]

29. Mourya, V.; Inamdar, N.N. Trimethyl chitosan and its applications in drug delivery. J. Mater. Sci.: Mater. Med. 2009, 20, 1057. [CrossRef]

30. Xiao, B.; Wan, Y.; Wang, X.; Zha, Q.; Liu, H.; Qiu, Z.; Zhang, S. Synthesis and characterization of N-(2-hydroxy) propyl-3-trimethyl ammonium chitosan chloride for potential application in gene delivery. Colloids Surf. B Biointerfaces 2012, 91, 168-174. [CrossRef]

31. Chen, K.-Y.; Zeng, S.-Y. Fabrication of quaternized chitosan nanoparticles using tripolyphosphate/genipin dual cross-linkers as a protein delivery system. Polymers 2018, 10, 1226. [CrossRef] [PubMed]

32. Wang, T.W.; Xu, Q.; Wu, Y.; Zeng, A.J.; Li, M.; Gao, H. Quaternized Chitosan (QCS) Nanoparticles as a Novel Delivery System for Ammonium Glycyrrhizinate. J. Nanosci. Nanotechnol. 2010, 10, 7402-7405. [CrossRef] [PubMed]

33. Mohy Eldin, M.S.; Omer, A.M.; Soliman, E.A.; Hassan, E.A. Superabsorbent Polyacrylamide Grafted Carboxymethyl Cellulose pH Sensitive Hydrogel: I. Preparation and Characterization. J. Desalination Water Treat. 2013, 51, 3196-3206. [CrossRef]

34. Mohamed, N.A.; Sabaa, M.W.; El-Ghandour, A.H.; Abdel-Aziz, M.M.; Abdel-Gawad, O.F. Quaternized N-substituted carboxymethyl chitosan derivatives as antimicrobial agents. Int. J. Biol. Macromol. 2013, 60, 156-164. [CrossRef] [PubMed]

35. Tamer, T.M.; Omer, A.M.; Hassan, M.A.; Hassan, M.E.; Sabet, M.M.; Mohy Eldin, M.S. Development of thermo-sensitive poly N-isopropyl acrylamide grafted chitosan derivatives. J. Appl. Pharm. Sci. 2015, 5, 1-6.

36. Basit, H.M.; Mohd Amin, M.C.I.; Ng, S.F.; Katas, H.; Shah, S.U.; Khan, N.R. Formulation and Evaluation of Microwave-Modified Chitosan-Curcumin Nanoparticles-A Promising Nanomaterials Platform for Skin Tissue Regeneration Applications Following Burn Wounds. Polymers 2020, 12, 2608. [CrossRef] [PubMed]

37. Sun, H.; Yu, J.; Gong, P.; Xu, D.; Zhang, C.; Yao, S. Novel core-shell magnetic nanogels synthesized in an emulsion-free aqueous system under UV irradiation for targeted radiopharmaceutical applications. J. Magn. Magn. Mater. 2005, 294, 273-280. [CrossRef] 
38. Morgen, M.; Tung, D.; Boras, B.; Miller, W.; Malfait, A.M.; Tortorella, M. Nanoparticles for improved local retention after intra-articular injection into the knee joint. Pharm. Res. 2013, 30, 257-268. [CrossRef]

39. Chu, X.Y.; Huang, W.; Wang, Y.L.; Meng, L.W.; Chen, L.Q.; Jin, M.J.; Chen, L.; Gao, C.H.; Ge, C.; Gao, Z.G. Improving antitumor outcomes for palliative intratumoral injection therapy through lecithin- chitosan nanoparticles loading paclitaxel-cholesterol complex. Int. J. Nanomed. 2019, 14, 689-705. [CrossRef]

40. Khezri, A.; Karimi, A.; Yazdian, F.; Jokar, M.; Mofradnia, S.R.; Rashedi, H.; Tavakoli, Z. Molecular dynamic of curcumin/chitosan interaction using a computational molecular approach: Emphasis on biofilm reduction. Int. J. Biol. Macromol. 2018, 114, 972-978. [CrossRef]

41. Sun, X.; Yu, D.; Ying, Z.; Pan, C.; Wang, N.; Huang, F.; Ling, J.; Ouyang, X.-k. Fabrication of Ion-Crosslinking Aminochitosan Nanoparticles for Encapsulation and Slow Release of Curcumin. Pharmaceutics 2019, 11, 584. [CrossRef]

42. Hasan, M.; Elkhoury, K.; Kahn, C.J.F.; Arab-Tehrany, E.; Linder, M. Preparation, Characterization, and Release Kinetics of Chitosan-Coated Nanoliposomes Encapsulating Curcumin in Simulated Environments. Molecules 2019, 24, 2023. [CrossRef] [PubMed]

43. Nasab, N.A.; Kumleh, H.H.; Beygzadeh, M.; Teimourian, S.; Kazemzad, M. Delivery of curcumin by a pH-responsive chitosan mesoporous silica nanoparticles for cancer treatment. Artif. Cells Nanomed. Biotechnol. 2018, 46, 75-81. [CrossRef] [PubMed]

44. Anitha, A.; Maya, S.; Deepa, N.; Chennazhi, K.P.; Nair, S.V.; Jayakumar, R. Curcumin-Loaded N,O-Carboxymethyl Chitosan Nanoparticles for Cancer Drug Delivery. J. Biomater. Sci. Polym. Ed. 2012, 23, 1381-1400. [CrossRef] [PubMed]

45. Kenawy, E.; Omer, A.; Tamer, T.; Elmeligy, M.; Eldin, M.M. Fabrication of biodegradable gelatin/chitosan/cinnamaldehyde crosslinked membranes for antibacterial wound dressing applications. Int. J. Biol. Macromol. 2019, 139, 440-448. [CrossRef] [PubMed]

46. Sun, X.; Liu, C.; Omer, A.M.; Yang, L.-Y.; Ouyang, X.-K. Dual-layered pH-sensitive alginate/chitosan/kappa-carrageenan microbeads for colon-targeted release of 5-fluorouracil. Int. J. Biol. Macromol. 2019, 132, 487-494. [CrossRef] [PubMed]

47. Hassan, M.A.; Tamer, T.M.; Valachová, K.; Omer, A.M.; El-Shafeey, M.; Mohy Eldin, M.S.; Šoltés, L. Antioxidant and antibacterial polyelectrolyte wound dressing based on chitosan/hyaluronan/phosphatidylcholine dihydroquercetin. Int. J. Biol. Macromol. 2021, 166, 18-31. [CrossRef] [PubMed]

48. Liang, X.X.; Omer, A.; Hu, Z.-H.; Wang, Y.G.; Yu, D.; Ouyang, X.-K. Efficient adsorption of diclofenac sodium from aqueous solutions using magnetic amine-functionalized chitosan. Chemosphere 2019, 217, 270-278. [CrossRef]

49. Sieval, A.; Thanou, M.; Kotze, A.; Verhoef, J.; Brussee, J.; Junginger, H. Preparation and NMR characterization of highly substituted N-trimethyl chitosan chloride. Carbohydr. Polym. 1998, 36, 157-165. [CrossRef]

50. Shao, Y.; Lin, A.H.-M. Improvement in the quantification of reducing sugars by miniaturizing the Somogyi-Nelson assay using a microtiter plate. Food Chem. 2018, 240, 898-903. [CrossRef] 